Revue de sciences sociales sur les arts, la culture et les idées

\title{
1 | 2017
}

Artistes ordinaires

\section{Une « théorie de la légitimité » revue et corrigée}

A "Theory of Legitimacy" Revised and Corrected

Una « teoría de la legitimidad » revisada y corregida

\section{Emmanuel Pedler}

\section{OpenEdition}

Journals

Édition électronique

URL : http://journals.openedition.org/bssg/145

DOI : $10.4000 /$ bssg. 145

ISSN : 2490-9424

Éditeur

Presses universitaires de Vincennes

Référence électronique

Emmanuel Pedler, « Une « théorie de la légitimité » revue et corrigée », Biens Symboliques / Symbolic Goods [En ligne], 1 | 2017, mis en ligne le 15 octobre 2017, consulté le 04 mars 2021. URL : http:// journals.openedition.org/bssg/145; DOI : https://doi.org/10.4000/bssg.145 

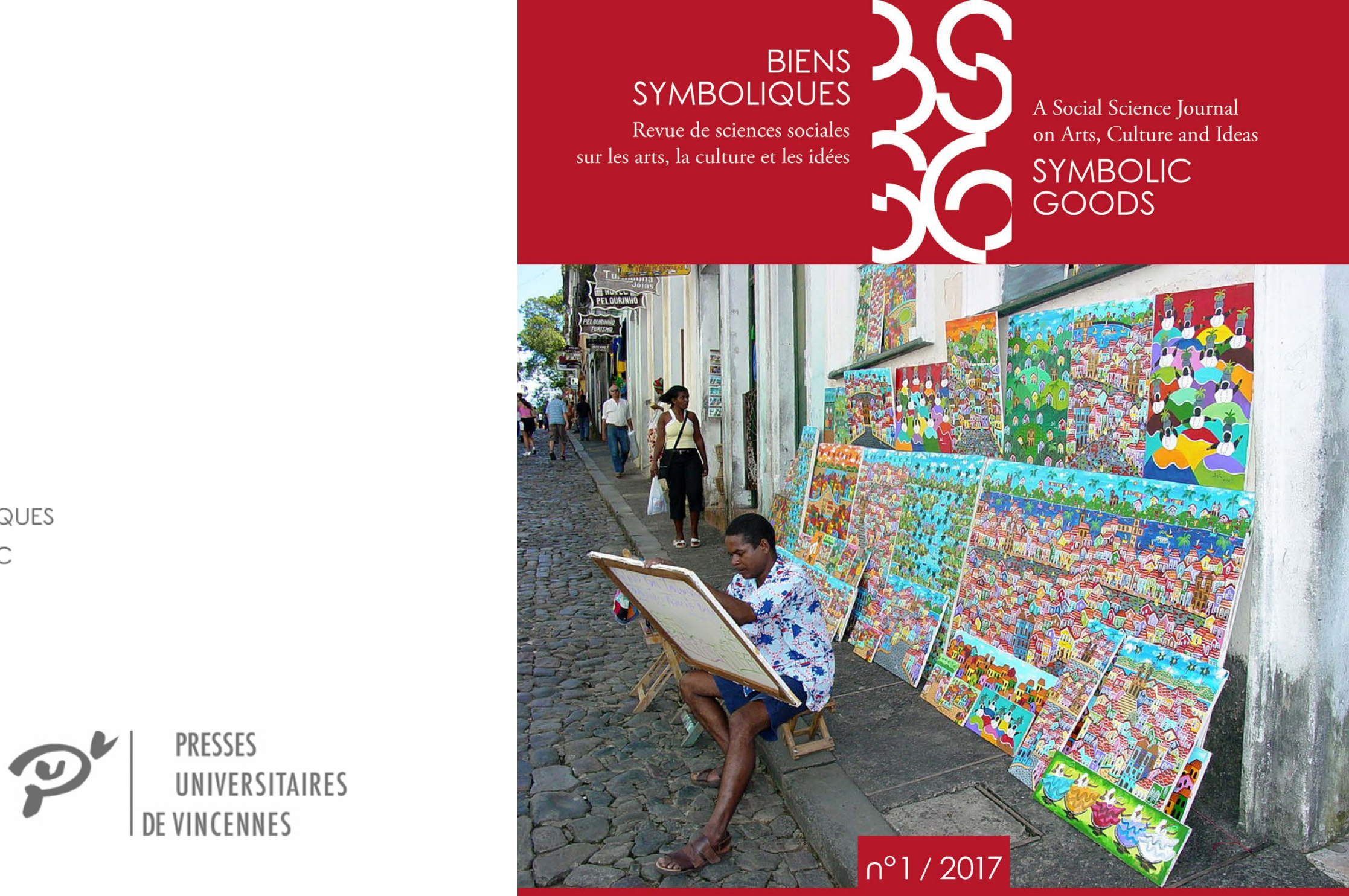

\section{Artistes ordinaires \\ Ordinary Artists}




\title{
Une « théorie de la légitimité » revue et corrigée
}

\author{
Emmanuel Pedler
}

Le Savant et le Populaire eut sans doute plus d'impact pour les sociologues de la culture du laboratoire dont je faisais partie - le Centre d'enquêtes et de recherches sur la culture, la communication, les modes de vie et la socialisation (CERCOM), qu'avait fondé Passeron et qui deviendra le laboratoire Sociologie, histoire, anthropologie des dynamiques culturelles (SHADyC) en 1993 - que Le Raisonnement sociologique, paru trois années plus tard (Passeron 2006/1991). Pour l'essentiel Le Savant et le Populaire donnait un signal clair en formalisant une critique nette des lectures bourdieusiennes, très systémiques, de la « théorie de la légitimité » tout en poursuivant un débat épistémologique serré. Pour les plus jeunes générations du cercle passeronien d'alors, l'interrogation principale était de savoir si le réformisme de Passeron allait assez loin. La réponse, comme la question du reste, était moins clairement formulée dans mon esprit qu'elle ne l'est aujourd'hui. Mais elle était déjà à l'œuvre, tout en portant la marque, en ce qui me concerne, de la lecture rapprochée des ouvrages de Weber et du démarrage, dès le début des années 1990, de l'entreprise de traduction et d'annotation de sa Sociologie de la musique (Weber 1998 [1921]), laquelle devait conduire à son édition chez Métaillé, une dizaine d'années après.

Ce retour à Weber, avec les deux impératifs épistémologiques de sa démarche - refus des systèmes, et description compréhensive du monde social - conduisait inévitablement à pousser la critique passeronienne beaucoup plus loin que ne le faisait Le Savant et le Populaire. Pour ouvrir l'analyse aux confrontations interculturelles et non plus exclusivement aux rapports lourds de domination, il suffisait donc, par construction, de poser l'importance de traiter des relations entre «cultures savantes et populaires » en ajoutant un pluriel décisif - le titre des 151 pages du chapitre central de l'ouvrage use d'un singulier, soulignons-le - et en constatant que les deux configurations n'étaient pas aussi distantes que les auteurs du Savant et le Populaire ne le prétendaient, mais placées dans une proximité ou une intersection partielle.

Les expériences de terrain faites à cette époque ont projeté rétrospectivement sur ces cadrages up-down une critique latente qui allait progressivement faire apparaître la « théorie de la légitimité " revue et corrigée de Passeron comme un réformisme qui faisait la moitié du chemin. La construction idéelle, très abstraite, très « a-priorique », de cette théorie saisissait de manière encore assez doctrinaire le monde bariolé des êtres et des choses, qui vont pourtant, dans la durée, selon leurs propres chemins (je pense à la formule wébérienne des enchaînements de circonstances).

La publication du séminaire, paru d'abord sous la forme d'un volume broché, a sollicité et fait réagir plusieurs chercheurs appartenant au Centre de recherche en sociologie de l'art et de la culture (CRESAC) et au CERCOM, laboratoires qu'avait fondés Passeron quelques années plus tôt. Comme 
je le notais plus haut, davantage que le Raisonnement sociologique, paru peu après, ce livre était de nature à susciter une réaction - allant de l'adhésion à l'adhésion critique - dans la mesure où il inscrivait une réflexion épistémologique au cœur même de débats concernant la sociologie de la culture, mais en se consacrant pour l'essentiel à cette dernière. À titre personnel, que ce soit à l'occasion de séminaires donnés à la Vieille Charité (le site marseillais de l'École des hautes études en sciences sociales) ou de lectures de l'ouvrage pour l'écriture d'articles, ce fut la deuxième option qui, graduellement, a donné forme à deux lectures critiques du texte. La première a été élaborée à partir de la montée en puissance de la dimension anthropologique dans mes cadrages théoriques qui, jusque-là, se concentraient exclusivement sur la sociologie de la culture. À partir d'une démarche descriptive de plus en plus ancrée et située, l'anthropologie culturelle allait prendre dans mes travaux la place centrale qu'elle occupe aujourd'hui dans L'Esprit des lieux (Pedler 2016). Par l'exploration des rationalisations techniques au principe de ce que l'on a appelé plus tard la numérimorphose, une seconde lecture critique a pris graduellement forme. La publication en 1985 de l'ouvrage L'CEil à la page par Passeron (1985) et la même équipe de recherche a, dans ce domaine, suscité pour ce qui me concerne la réalisation d'une enquête à laquelle je me suis attelé avec Olivier Zerbib quelques années plus tard.

Celle-ci a abouti à la publication de l'ouvrage Les Nouvelles Technologies à l'épreuve des bibliothèques (Pedler \& Zerbib 2001), qui portait en germe une série d'interrogations, de perplexités, de questions sans réponse, mais également d'insatisfactions face à ce que j'appelais alors la théorie réformiste de la légitimité de Passeron. II faut ajouter que la nature même des objets symboliques qui allaient subir, de la fin des années 1990 à aujourd'hui, une mutation et un déploiement social, culturel et technologique dont la forme n'était pas alors prévisible, mettait à rude épreuve les cadres théoriques du livre qui nous occupe. Parallèlement, les ambiguïtés et les faiblesses de la notion d'art moyen - l'ouvrage piloté par Pierre Bourdieu ne porte pas la signature passeronienne, il importe de le souligner ici - faisait craquer de toutes parts le constructivisme qui avait présidé à l'élaboration de la « théorie de la légitimité » en sa version bourdieusienne. Si l'on entend par constructivisme une démarche selon laquelle notre vision de la réalité est, non le reflet de la réalité elle-même, mais le produit de l'esprit humain en interaction avec cette réalité, force est d'admettre que le réglage épistémologique le plus délicat concerne le degré de cette interaction. Ainsi la proposition culturaliste et germinative du Savant et le Populaire - « dans quelque condition sociale qu'elle fonctionne, une culture tend toujours à s'organiser comme système symbolique » (Grignon \& Passeron 1989 : 18) - maintient le curseur constructiviste à un degré élevé, tout en récusant la tripartition arts savants/art moyen/art populaire qui ne ferait qu'obscurcir la description des pratiques situées et la compréhension des relations entre cultures savantes et cultures hétéronomes.

La confrontation répétée à des terrains d'enquête a fait progressivement apparaître à mes yeux les faiblesses d'une démarche que je qualifie aujourd'hui de « sociologiste » et de « discontinuiste » dans L'Esprit des lieux (Pedler 2016 : 37-48). C'est donc une critique méthodologique frontale qui 
s'exprime alors, pour aller en s'affirmant dans les décennies qui suivront, à l'égard d'analyses sociologiques utilisant les notions d'indicateurs et de corrélations. II faut ajouter que dans Le Savant et le Populaire les développements empiriques semblent se déployer exclusivement sous la forme qualitative de témoignages, entretiens ou extraits littéraires. Ils s'inscrivent pourtant dans ce périmètre méthodologique quantitatif qui était, du reste, l'horizon principal sur lequel travaillait alors Passeron. La réalisation du Temps donné aux tableaux (Passeron \& Pedler 1991) en porte directement témoignage.

En adoptant le point de vue de l'anthropologie culturelle, il devenait urgent d'explorer préalablement l'épaisseur de cas et de configurations observées en situation. Cet impératif entrait dès lors en contradiction avec les cadres de la théorie de la légitimité, même en sa version amendée - des cadres trop catégoriquesquiprésupposaientl'existenced'entités distinctes comme les milieux, les classes ou les registres d'action. Telles étaient du reste les catégories principales utilisées dans les enquêtes d'alors, déployées dans le laboratoire, à travers des variables d'état - allant des Pcs à divers indicateurs de milieux - censées identifier synthétiquement l'ethos des groupes d'enquêtés, toujours pensés comme faisant partie de collectifs. Ainsi la catégorisation des registres de pratiques - je pense en particulier à l'opposition entre le fonctionnel et l'esthétique, réaffirmée dans Le Savant et le Populaire - est alors maintenue par les auteurs qui, dans le même mouvement, prolongent une critique en direction du systémisme bourdieusien à propos de ce que les auteurs appellent le « coup de la nécessité » et la rhétorique du goût.
Cette position d'entre-deux ne résiste pourtant pas à l'épreuve empirique puisque les «cas » cités à l'appui de ce type d'analyse (Grignon \& Passeron 1989 : 109-110) sont présentés à partir d'une description décharnée, brève et totalement décontextualisée, selon un mode opératoire pour lequel l'ethnographie n'est qu'illustrative et n'est mobilisée que pour donner l'illusion de replonger dans la réalité des interactions ordinaires, sans se donner les moyens de décrire comment, en situation, diverses dimensions des pratiques sont articulées les unes aux autres.

Mais c'est avant tout à partir du paradoxe de l'indicateur géographique résiduel que les limites des outils méthodologiques objectivistes (indicateurs, corrélations) sont apparues les plus criantes. On peut résumer ce paradoxe de la manière suivante : la liste complète des indicateurs d'une enquête est affectée d'une dissymétrie troublante. Si l'on peut penser ces indicateurs dans le cadre des algorithmes des régressions - toute dimension apportant une contribution, cumulative -, une semblable intégration de la dimension localisée du phénomène étudié relève d'une fiction qui refuse de mesurer la singularité de cette « variable ». Celle-ci recèle en effet des propriétés qui débordent les autres dimensions et ne constitue en aucun cas une variable comme les autres. C'est ainsi que les propriétés des comportements liés à l'origine géographique des enquêtés n'arrivent pas à être explicitées par l'ensemble des autres variables de l'enquête - qui, pourtant, prétendent épuiser les différentes composantes de l'ethos des enquêtés. Ce fut le cas, par exemple, des recherches portant sur les pratiques des festivaliers du Festival international de théâtre 
d'Avignon (Pedler \& Bourbonnaud 2002a et 2002b) ou sur les pratiques de lecture pour les différents sites de l'enquête à l'origine de l'ouvrage Les Nouvelles Technologies à l'épreuve des bibliothèques. On peut déduire de ce paradoxe que la singularité des pratiques sociales et culturelles, dès lors qu'elle ne peut exister qu'implémentée dans un contexte social et historique précis, déborde largement ce qu'une sociologie objectiviste peut en dire.

Emmanuel Pedler PSL-EHESS, Centre Norbert Elias http://centre-norbert-elias.ehess.fr/

\section{Références bibliographiques}

Aron Raymond (1983). Mémoires. Paris, Julliard.

BAKHTINE Mikhaïl (1970). L'CEuvre de François Rabelais et la culture populaire au Moyen Âge et sous la Renaissance. Paris, Gallimard.

BECKER Howard (1988). Les Mondes de l'art. Traduit de l'anglais par Jeanne Bouniort. Paris, Flammarion.

BeLlavance Guy, Boivin Micheline, SANTerRe Lise (dir) (2000). Démocratisation de la culture ou démocratie culturelle ? Deux logiques d'action publique. Québec, Éditions de l'IQRC.

Bols Géraldine (2008). " Le consentement à la domination littéraire. Degrés et diversité de ses formes chez les écrivains "les moins reconnus" de l'univers littéraire ». Tracés, $14: 55-76$.

Bourdieu Pierre (1979). La Distinction. Critique sociale du jugement. Paris, Minuit.

BouRdieu Pierre (1984). Questions de sociologie. Paris, Minuit.

BOURDIEU Pierre (1988). «Entretien recueilli par Beate Krais ». In BOURDIEU Pierre, Chamboredon Jean-Claude, PAsseron Jean-Claude, Le Métier de sociologue. Préalables épistémologiques. Paris, Éditions de l'EHESS (cinquième édition)

BouRdieu Pierre (1989). La Noblesse d'État. Paris, Minuit.
BouRdieu Pierre (1993). « Les contradictions de l'héritage ». In Bourdieu Pierre (dir.), La Misère du monde. Paris, Seuil : 711-718.

BouRdieu Pierre (1998) [1992]. Les Règles de l'art. Genèse et structure du champ littéraire. Paris, Seuil.

BOURDIEU Pierre (1998). La Domination masculine. Paris, Seuil.

Bourdieu Pierre (2003) [1997]. Méditations pascaliennes. Paris, Seuil.

Bourdieu Pierre, Chamboredon Jean-Claude, Passeron Jean-Claude (1968). Le Métier de sociologue. Paris, Mouton.

Bourdieu Pierre \& PAsSeron Jean-Claude (1964). Les Héritiers. Les étudiants et la culture. Paris, Minuit.

BOURDIEU Pierre \& PASSERON Jean-Claude (1970). La Reproduction. Éléments pour une théorie du système d'enseignement. Paris, Minuit.

BOURDIEU Pierre \& WACQUANT Loïc (2014). Invitation à la sociologie réflexive. Paris, Seuil.

BOUTIER Jean (2008). "Quelques réflexions rétrospectives sur les histoires de la "culture populaire" ». Journée d'étude "Le Savant et le Populaire, 1989-2008. Retour sur un débat en suspens ». SHADYC, EHESS Marseille (non publié).

BOUVERESSE Jacques (2008). « Le besoin de croyance et le besoin de vérité ». Agone, 38-39: 281-306.

BURKE Peter (1978). Popular Culture in Early Modern Europe. Londres, Temple Smith.

BuscatTo Marie (2014). Sociologies du genre. Paris, Armand Colin.

Busino Giovanni (2006). «Entretien avec Dominique Schnapper ». Revue européenne des sciences sociales, XLIV(135). [En ligne] http://ress. revues.org/271 [consulté le 12 octobre 2016].

CASANOVA Pascale (2008) [1999]. La République mondiale des lettres. Paris, Seuil.

CHAPOULIE Jean-Michel (1991). « La seconde fondation de la sociologie française, les États-Unis et la classe ouvrière ». Revue française de sociologie 32(3) : 321-364.

CHARTIER Roger (2001). "Culture écrite et littérature à l'âge moderne 》. Annales. Histoire, Sciences sociales, 56(4) : 783-802.

COHEN Déborah (2010). La Nature du peuple. Les formes de l'imaginaire social (XVIII/ $\left.X X\right|^{e}$ siècles). Seyssel, Champ Vallon. 
COLleCtIF (1988). « Histoire et sciences sociales. Un tournant critique ? ". Annales ESC, 2 : 291-293.

Collectif Révoltes logiques (1984). L'Empire du sociologue. Paris, La Découverte.

Collovald Annie (1988). "Identité(s) stratégiques(s) », Actes de la recherche en sciences sociales, $73: 29-40$.

Connell Raewyn (1995). Masculinities. Cambridge, Polity Press.

CoRnu Tanguy (2008). « L'ambiguïté du concept de domination symbolique dans Le Savant et le Populaire ". Journée d'étude "Le Savant et le Populaire, 1989-2008. Retour sur un débat en suspens ». SHADYC, EHESS Marseille (non publié).

CoULANGEON Philippe \& DuvAL Julien (2013). Trente ans après La Distinction de Pierre Bourdieu. Paris, La Découverte.

COULANGEON, Philippe \& DUVAL Julien (2013). «Introduction ». In EID. (dir.), Trente ans après La Distinction de Pierre Bourdieu. Paris, La Découverte. Daudet Alphonse (1868). Le Petit Chose. Paris, Pierre-Jules Hetzel.

DeBEAUvaIs Michel (1976). L'Université ouverte : les dossiers de Vincennes. Grenoble, Presses Universitaires de Grenoble.

Dragomir Lucia (2011). «L'Union des écrivains. Un modèle institutionnel et ses limites ». Vingtième siècle, $109: 59-70$.

Ducournau Claire (2017). "Les deux (ou trois) carrières de Richard Hoggart. De la fondation des cultural studies aux appropriations de la sociologie française ". Revue d'anthropologie des connaissances, 11(3) : 263-282.

DUMONT Fabienne \& SoFIO Séverine (2007). " Esquisse d'une épistémologie de la théorisation féministe en art ». Cahiers du genre, 43 : 17-43.

DuVAL Julien (2010). "Distinction studies ». Actes de la recherche en sciences sociales, 181-182 : 146-156.

ELIAS Norbert (1991). La Société des individus. Traduit de l'allemand par Jeanna Etoré. Paris, Fayard.

FABIANI Jean-Louis (dir.) (2001). Le Goût de l'enquête. Pour Jean-Claude Passeron. Paris, L'Harmattan.

FossÉ-PolıAK Claude (2006). Aux frontières du champ littéraire. Sociologie des écrivains amateurs. Paris, Économica.

FouCAult Michel (1973). Moi, Pierre Rivière ayant égorgé ma mère, ma sœur et mon frère... Paris, Gallimard/Julliard.
FoucAult Michel (1994). Dits et écrits, t. 1 et 2. Paris, Gallimard.

Gaboriau Philippe (1995). Le Tour de France et le vélo. Histoire sociale d'une épopée contemporaine. Paris, L'Harmattan.

GABORIAU Philippe (2003). Les Spectacles sportifs. Grandeurs et décadences. Paris, L'Harmattan.

GinzBURG Carlo (1980) [1976]. Le Fromage et les vers. L'univers d'un meunier du $\mathrm{XV}^{e}$ siècle [II formaggio e i vermi. II cosmo di un mugnaio del Cinquecento, Turin, Einaudi]. Traduit de l'italien par Monique Aymard. Paris, Flammarion.

Grenier Jean-Yves, Grignon Claude, Menger Pierre-Michel (dir.) (2001). Le Modèle et le récit. Paris, Maison des Sciences de l'Homme.

GriGnon Claude (1996). " Le savant et le lettré, ou l'examen d'une désillusion ", Revue européenne des sciences sociales, $103:$ 81-98.

GRIGNON Claude (2001). "La formalisation et les sciences du récit, le cas de la sociologie ». In Grenier Jean-Yves, Grignon Claude, Menger Pierre-Michel (dir.), Le Modèle et le récit. Paris, Maison des Sciences de l'Homme : 7-43.

Grignon Claude \& Kordon Claude (dir.) (2009). Sciences de l'homme et sciences de la nature, essais d'épistémologie comparée. Paris, Maison des Sciences de l'Homme.

GRIGNON Claude \& PASSERON Jean-Claude (1982). Sociologie de la culture et sociologie des cultures populaires. Paris, Documents du GIDES, 4. Grignon Claude \& PAsseron Jean-Claude (1985). Enquête. Cahiers du CERCOM, 1 («À propos des cultures populaires »). [En ligne] https:// enquete.reveues.org/2 [consulté le 26 juin 2017].

Grignon Claude \& PASSERON Jean-Claude (2015) [1989]. Le Savant et le Populaire. Misérabilisme et populisme en sociologie et en littérature. Paris, Seuil, «Points 》 [1 $1^{\text {re }}$ éd. Gallimard/Seuil, « Hautes études 》]. En espagnol : GRIGNON Claude \& PASSERON Jean-Claude (1991). Lo culto y lo popular : miserabilismo y populismo en sociologia y en literatura. Traduction de María Sonderéguer. Buenos Aires, Ediciones Nueva Vision Grignon Claude \& PASSERON Jean-Claude (1992). Lo culto y lo popular : miserabilismo y populismo en sociologia y en literatura. Traduction de Fernando Alvarez-Uria et Julia Varela. Madrid, Las Ediciones de La Piqueta. 
Grignon Claude, Collovald Annie, Pudal Bernard, Sawicki Frédéric (1991). « Un savant et le populaire. Entretien avec Claude Grignon ». Politix, $13:$ :35-42.

GRUEL Louis (2004). La Rébellion de 68. Une relecture sociologique. Rennes, Presses Universitaires de Rennes.

GuILLAUMIn Colette (2002) [1972]. L'ldéologie raciste. Paris, Gallimard.

HALL Stuart \& JefFERSON Tony (dir.) (1976). Resistance through Rituals : Youth Subcultures in Post-War Britain. Londres, Hutchinson.

Hammou Karim (2008). «Penser le pouvoir avec Le Savant et le Populaire ». Journée d'étude «Le Savant et le Populaire, 1989-2008. Retour sur un débat en suspens ». SHADYC, EHESS Marseille (non publié).

HEINICH Nathalie (2000) [1991]. Être écrivain. Paris, La Découverte.

HoggaRT Richard (1970a). La Culture du pauvre. Étude sur le style de vie des classes populaires en Angleterre. Traduit de l'anglais par Françoise Garcia, Jean-Claude Garcia et Jean-Claude Passeron, présentation et index de Jean-Claude Passeron (titre original The Uses of Literacy : Aspects of Working Class Life). Paris, Minuit.

HogGaRT Richard (1970b). Speaking to Each Other, vol. 1. Londres, Chatto et Windus.

HoggaRT Richard (2013) [1991]. 33 Newport Street. Autobiographie d'un intellectuel issu des classes populaires anglaises. Traduit de l'anglais par Christiane Grignon \& Claude Grignon avec la collaboration de Christopher Todd, présentation de Claude Grignon. Paris, Seuil, «Points »

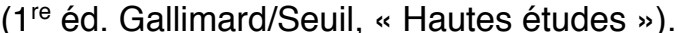

KalIFA Dominique (2005). «Les historiens français et le "populaire" ». Hermès, $42: 54-59$.

KRÉFA Abir (2013). «La quête de l'autonomie littéraire en contexte autoritaire : le cas des écrivains tunisiens ». Sociologie, $4: 395-411$.

KRÉFA Abir (2013). Activités littéraires et rapports sociaux de sexe : le cas des écrivains tunisiens (thèse de doctorat en sociologie). Lyon, Université Lyon 2.

KRÉFA Abir (2014). «Entre injonctions à dire et à taire le corps : les voies étroites de la reconnaissance littéraire pour les écrivaines tunisiennes ». Ethnologie française, 44(4) : 631-642.
LAgRAVE Rose-Marie (1980). Le Village romanesque. Le Paradou, Actes Sud, « Espace-temps ».

LAGRAVE Rose-Marie (1988). "Mensonge romanesque et vérité des romanciers. Une relecture du Village Romanesque ». Études Rurales, $109: 55-73$.

LAGRAVE Rose-Marie (2009). « Filiations intellectuelles et espérance sociale. Figure et œuvre de Placide Rambaud ». Études rurales, 183 51-66.

Lagrave Rose-Marie (2010). «Se ressaisir ». Genre, Sexualité \& Société, 4 : 1-17. [En ligne] http://gss.revues.org

LAHIRE Bernard (2004). La Culture des individus : dissonances culturelles et distinction de soi. Paris, La Découverte.

LAHIRE Bernard (2008). La Raison scolaire. École et pratiques d'écriture, entre savoir et pouvoir. Rennes, Presses Universitaires de Rennes.

LAHIRE Bernard (2012). Monde pluriel. Penser l'unité des sciences sociales. Paris, La Découverte.

LAMONT Michèle (1995). La Morale et l'argent : les valeurs des cadres en France et aux États-Unis. Paris, Métailié.

LAMONT Michèle (2013). «En quoi Bourdieu a-t-il été utile à notre réflexion ? Le cas des États-Unis ». In CoulAngEON Philippe \& DuvaL Julien (dir.), Trente ans après La Distinction de Pierre Bourdieu. Paris, La Découverte : 59-68

Levı Giovanni (1989). Le Pouvoir au village. Histoire d'un exorciste dans le Piémont du XVI/ siècle. Paris, Gallimard.

LINHART Robert (1981). L'Établi. Paris, Minuit.

MACKENZIE Caroline (2012). "Agency, un mot, un engagement ». Rives méditerranéennes, 41(1). [En ligne] http://rives.revues.org/4139 [consulté le 11 mars 2017].

Mathieu Nicole-Claude (1991). L'Anatomie politique. Paris, Côté-Femmes. MAUGER Gérard (1991). «Enquêter en milieu populaire ». Genèses, 6 : 125-143.

MAUGER Gérard (2005). « Un apprentissage tardif du métier de sociologue ». In MAUGER Gérard (dir.), Rencontres avec Pierre Bourdieu. Bellecombe-en-Bauges, Le Croquant : 239-257. 
MAuger Gérard (2006a). «Sur la violence symbolique ». In MüLleR HansPeter \& Sintomer Yves (dir.). Pierre Bourdieu, théorie et pratique. Paris, La Découverte : 84-100.

MAUGER Gérard (2006b). Les Bandes, le milieu et la bohème populaire. Études de sociologie de la déviance des jeunes des classes populaires (1975-2005). Paris, Belin.

MAUGER Gérard (2013). « Bourdieu et les classes populaires. L'ambivalence des cultures dominées ». In CoulangEON Philippe \& DUVAL Julien (dir.), Trente ans après La Distinction de Pierre Bourdieu. Paris, La Découverte : 243-254

MAUGER Gérard (2014). « Domination ». Le Lexique socius. [En ligne] http:// ressources-socius.info/index.php/lexique/21-lexique/154-domination [consulté le 14 janvier 2017].

MAUGER Gérard \& Fossé Claude (1977). La Vie buissonnière. Marginalité petite-bourgeoise et marginalité populaire. Paris, Maspero.

MAUgeR Gérard \& Fossé-PoliaK Claude (1985). « Choix politiques et choix de recherches. Essai d'auto-socio-analyse (1973-1984) ». Cahiers « Jeunesses et Sociétés », 3-4-5: 27-121.

MengeR Pierre-Michel (2009). Le Travail créateur. S'accomplir dans l'incertain. Paris, Gallimard/Seuil, « Hautes études ».

MorRIson Toni (1990). Playing in the Dark: Whiteness and The Literary Imagination. New York, Vintage Books.

Moulin Raymonde (1971). «La Culture du pauvre. À propos du livre de Richard Hoggart ». Revue française de sociologie, 12(2) : 255-258.

Moulin Raymonde (1992). L'Artiste, l'institution et le marché. Paris, Flammarion.

Moulin Raymonde(dir.) (1986). Sociologie del'art. Paris, La Documentation française.

Moulin Raymonde, PAsseron Jean-Claude, PAsquier Dominique, PortoVAsquez Fernando (1985). Les Artistes, essai de morphologie sociale. Paris, La Documentation Française.

NAUDIER Delphine \& ROLLET Brigitte (2007). Genre et légitimité culturelle Quelle reconnaissance pour les femmes ?. Paris, L'Harmattan.

NAVEL Georges (1945). Travaux. Paris, Gallimard.

NeVEU Érik (1999). “ Pour en finir avec l'enfantisme. Retours sur enquêtes ». Réseaux, 92-93:175-201.
Neveu Erik (2008). « Les voyages des cultural studies ». L'Homme, 187$188: 315-341$.

NoIRIEL Gérard (1988). Le Creuset français. Histoire de l'immigration $\left(X I X^{e}-X X^{e}\right.$ siècle). Paris, Seuil.

OlivieR DE SARDAN Jean-Pierre (2008). La Rigueur du qualitatif. Les contraintes empiriques de l'interprétation socio-anthropologique. Louvain Bruylant Academia.

PARETo Vilfredo (1917). Traité de sociologie générale. Traduit de l'italien par Pierre Boven. Lausanne, Payot.

PAsquali Paul \& Schwartz Olivier (2016). « La Culture du pauvre : un classique revisité. Hoggart, Les classes populaires et la mobilité sociale ». Politix, 114 : 21-45.

Pasqual Paul (2014). Passer les frontières sociales. Comment les " filières d'élite » entrouvrent leurs portes. Paris, Fayard.

PAsquier Dominique (1989). La Culture des sentiments. L'expérience télévisuelle des adolescents. Paris, Éditions de la MSH.

PASQUIER Dominique (2005). " La "culture populaire" à l'épreuve des débats sociologiques ». Hermès, 42 : 60-69.

PASSERON Jean-Claude (2006) [1991]. Le Raisonnement sociologique. Un espace non poppérien de l'argumentation. Paris, Albin Michel, nouvelle édition revue et augmentée (première édition Paris, Nathan).

Passeron Jean-Claude \& Pedler Emmanuel (1991). Le Temps donné aux tableaux. Compte rendu d'une enquête au musée Granet. Marseille, Imerec.

PAsseron Jean-Claude \& GRUMBACH Michel (dir.) (1985). L'CEil à la page enquête sur les images et les bibliothèques. Paris, Bibliothèque publique d'information, Service des études et de la recherche.

PASSERON Jean-Claude (dir.) (1999). Richard Hoggart en France. Paris, Bibliothèque publique d'information.

PedLer Emmanuel (2010). « Les sociologies de la musique de Max Weber et Georg Simmel. Une théorie relationnelle des pratiques musiciennes ». L’Année sociologique, 60(2) : 305-330.

Pedler Emmanuel (2016). L'Esprit des lieux. Paris, Éditions de l'EHESS. Pedler Emmanuel \& Bourbonnaud David (2002a). « L'offre du festival "in" d'Avignon : effet d'imposition ou stimulation culturelle ? ". Actes du colloque d'Amiens. 
Pedler Emmanuel \& Bourbonnaud David (2002b). « La programmation du Festival. Un pacte de confiance entre l'organisation festivalière et son public ». In ETHIS Emmanuel (dir.), Avignon : le public réinventé. Paris, La Documentation française : 131-159.

Pedler Emmanuel \& Zerbib Olivier (2001). Les Nouvelles Technologies à l'épreuve des bibliothèques. Paris, Bibliothèque publique d'information. Peterson Richard A. \& Simkus Albert (1992). " How Musical Tastes Mark Occupational Status Groups ». In LAMONT Michèle \& FouRNIER Marcel, Cultivating differences : Symbolic Boundaries and the Making of Inequality. Chicago, The University of Chicago Press : 152-168.

Peterson Richard A. (1992). " Understanding audience segmentation :

From elite and mass to omnivore and univore ». Poetics, 21(4) : 243-258.

Peterson Richard A. (1997). "The Rise and Fall of Highbrow Snobbery as a Status Marker ». Poetics, 25(2-3) : 75-92.

Peterson Richard A. \& Kern Roger M. (1996). " Changing Highbrow Taste : from Snob to Omnivore ». American Sociological Review, 61(5) : 900-907.

PUDAL Bernard (1991). « Le populaire à l'encan ». Politix, 13 : 53-64.

RANCIĖRE Jacques (1981). La Nuit des prolétaires. Archives du rêve ouvrier. Paris, Fayard.

RANCIÈRE Jacques (2011). La Leçon d'Althusser. Paris, La Fabrique.

ReVEL Jacques (dir.) (1996). Jeux d'échelles. La micro-analyse à l'expérience. Paris, Gallimard/Seuil.

RoBinson Eric E. (1968). The New Polytechnics. The People's Universities. Harmondsworth, Penguin.

RoEDIGER David (1991). The Wages of Whiteness : Race and the Making of the American Working Class. New York, Verso.

SAPIRO Gisèle (2013a). "La carrière internationale de La Distinction ». In COULANGEON Philippe \& DUVAL Julien (dir.), Trente ans après La Distinction de Pierre Bourdieu. Paris, La Découverte : 45-58

SAPIRO Gisèle (2013b). « Le champ est-il national ? La théorie de la différenciation sociale au prisme de l'histoire globale ". Actes de la recherche en sciences sociales, $200: 70-85$.

SCHILLING Heinz (1981). Konfessionskonflikt und Staatsbildung. Eine Fallstudie über das Verhältnis von religiösem und sozialem Wandel in der Früh Neuzeit am Beispiel der Grafschaft Lippe. Gütersloh, Bertelsmann.
ScotT James (2008). La Domination et les arts de la résistance. Fragments du discours subalterne. Traduction française par Olivier Ruchet. Paris, Éditions Amsterdam.

Servien Pius (1935). Principes d'esthétique. Problèmes d'art et langage des sciences. Paris, Boivin.

SINGLY François (DE) (1998). "Bourdieu : nom propre d'une entreprise collective ». Le Magazine littéraire, 369 : 39-44.

SUTTON-SMitH Brian (1970). "Psychology of Childlore : The Triviality Barrier ». Western Folklore, 29(1) : 1-8.

TAINE Hyppolite (1858). Essais de critique et d'histoire. Paris, Hachette. VEYNE Paul (1971). Comment on écrit l'histoire. Essai d'épistémologie. Paris, Seuil.

VEYNE Paul (2008). Foucault. Sa pensée, sa personne. Paris, Albin Michel. Weber Max (1998) [1921]. Sociologie de la musique. Les fondements rationnels et sociaux de la musique [Die rationalen und soziologischen Grundlagen der Musik, Tübingen, Drei Masken Verlag]. Traduit de l'allemand par Jean Molino et Emmanuel Pedler. Paris, Métailié.

Wimmer Andreas \& Glick Schiller Nina (2002). " Methodological Nationalism and Beyond : Nation-State Building, Migration and the Social Sciences ». Global Network, 2 : 301-334. 